\title{
Enhancing the performance of distance protection relays using interactive control system
}

Salah K. El-Sayed, Hassan S. Mohamed

Al-Azhar University, Nasr city, Cairo, Egypt

\begin{tabular}{l}
\hline \hline Article Info \\
\hline Article history: \\
Received Aug 9, 2018 \\
Revised Sep 21, 2018 \\
Accepted Oct 3, 2018 \\
\hline
\end{tabular}

\section{Keywords:}

DIgSILENT

Distance relay

SCADA system

\begin{abstract}
Improvement of automation systems for electrical power system network became essential for increasing the realiability of power transmission during any disturbance. In most substations the settings of Distance Relays (DRs) are set manually which depends on human experience this may be led to undesirable operations. Any power transmission system may subjected to shortens and loss of adjusting its protection setting, DRs in protection systems are responsible for protecting High voltage transmission lines from short circuit, power swing, and load encroachment, A proposes automation system architecture introduced to cover the setting and coordination of protection scheme based on DIgSILENT power factory, SIMATIC manger, and WinCC programs.
\end{abstract}

Copyright $(2) 2019$ Institute of Advanced Engineering and Science. All rights reserved.

\section{Corresponding Author:}

Hassan S. Mohamed, Al-Azhar University, Nasr city, Cairo, Egypt.

Email: h_alazhary@yahoo.com

\section{INTRODUCTION}

The best protection technique achieves isolation the fulty section quickly beside maintaining protection objectives realiability, and dependability [1-2]. Distance relays are one of the most important protection elements in a transmission line [3-4]. The reliable operation of protection systems depends on the correct design and protection settings within protective devices [5].

Nowadays, System topology changes continuously due to the addition of new generation units, transmission lines and multiple switching actions due to maneuverings and maintenance, these actions affect on protection system settings [6-7]. To make DRs diagnosis the fult correct with fast of response and minimum disturbance $[2,8,9]$, a supervisory control and data acquisition system (SCADA) sends correct settings to the protection devices. A SCADA system consists of a number of programmable logic controller (PLC) or remote terminal unit (RTUs) communicates with all protection devices and network topology status and sends/Receives data with master station via a communications system [10]. the master station works as interactive control system based on DIgSILENT power factory protection coordination results to enhance the relay performance, these results to be sent to protection devices.

\section{DISTANCE RELAY CONSTRUCTION, SETTINGS, AND OPERATION}

\subsection{Relay construction}

Numerical design techniques recently used in relay construction, mostly consists of:

\subsubsection{Analogue measuring}

Inputs transform the currents and voltages derived from the instrument transformers and match them to the internal signal levels for processing in the relay. 


\subsubsection{Micro computer system $(\mu \mathrm{C})$ :}

Apart from processing the measured values, the microcomputer system also executes protection schem according to settings.

\subsubsection{Binary Inputs and Outputs:}

$\mu \mathrm{C}$ obtains external information through binary inputs such as blocking commands for protective elements, also issues information to external equipment via the output contacts. These outputs include, in particular, trip commands to circuit breakers.

\subsubsection{Communication ports:}

For remote communications via a modem, or local communications via a substation master computer [11].

\subsection{Relay setting and Operation}

Distance relay basically determines the line impedance by comparing the voltage and current values according to equation $\mathrm{Z}=\mathrm{V} / \mathrm{I}$. If the measured impedance value of relay is smaller than the previously entered relay zone setting then relay operates and generates trip signal. Distance protection relays have different types of characteristics such as impedance, reactance, mho and polygon, the last one is used in this manuscript [7, 12]. Purpose of coordination, a basic distance protection scheme consists of three zones of protection, Figure 1 shows the zone impedances and corresponding tripping time. Zone impemance settings are determined as following:

$$
\begin{aligned}
& Z 1=\text { Zline } 1 \times 80 \% \\
& Z 2=\text { Zline } 1+\text { Zline } 2 \times 60 \% \\
& Z 3=\text { Zline } 1++ \text { Zline } 2+Z \text { line } 3 \times 20 \%
\end{aligned}
$$

In case of parallel lines

$$
\begin{aligned}
& \mathrm{Z} 1=\mathrm{Zline} 1 \times 80 \% \\
& \mathrm{Z} 2=\mathrm{Zline} 1+\mathrm{Zline} 2 \times 60 / 2 \% \\
& \mathrm{Z} 3=\mathrm{Zline} 1++\mathrm{Zline} 2 \times 60 \%
\end{aligned}
$$

Time setting for Zone 1 is usually set to instantaneous trip, Zone 2 protection must be time delayed by $350 \mathrm{~ms}$ so that discrimination can be achieved with the zone 1 protection on the adjacent circuit, and Zone 3 has a longer time delay than zone 2, typically $700 \mathrm{~ms}$. Sometimes this zone is set to look in a reverse direction to provide backup for bus protection systems [7, 12, 13].

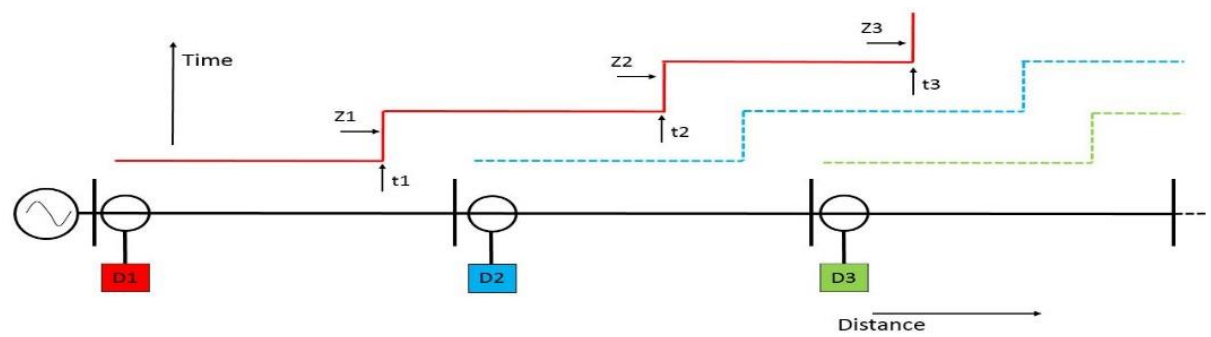

Figure 1. Relay zones

\section{SCADA SYSTEM CONFIGURATION}

SCADA system architecture proposed is shown in Figure 2, and it is summarized as follows for controling and monitoring functions. Field devices: which represented in our proposed system as DRs. Controller: is a PLC which works as main brain, sends/recives data between SCADA server and DRs. Network: which is the physical link between SCADA system components. SCADA Server and Operator stations: are 
used to display real-time data receives/sends from the protection devices, keeps history records, also can be used for diagnosing system faults [14-17].

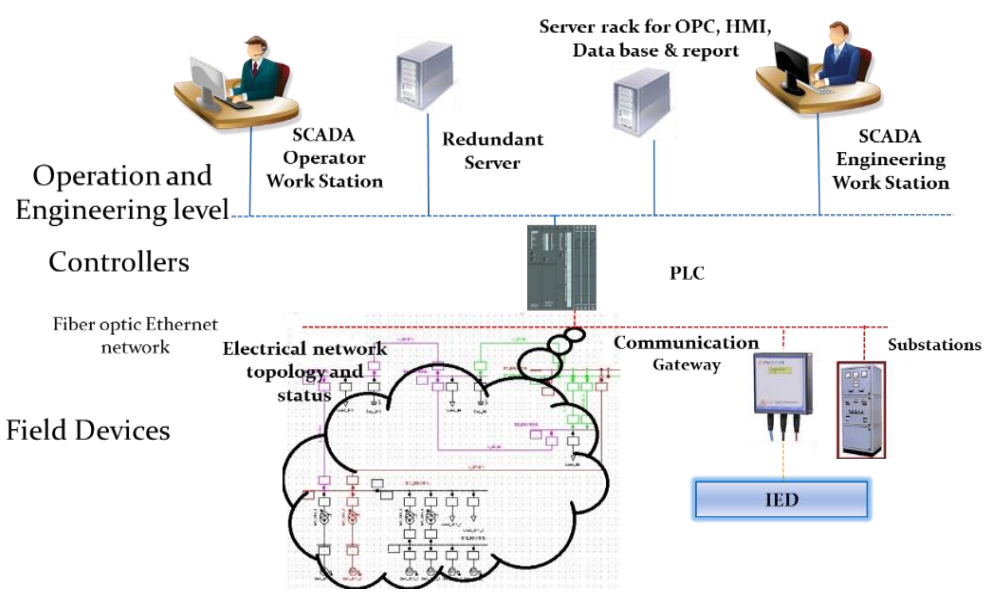

Figure 2. Proposed automation system for electrical network and protection devices

\section{CASE STUDY}

Power systems are complex dynamic systems which parameters and states vary continuously, these variations linked to zone settings of a distance relay [19]. the sequence of evaluating work could explained as shown in Figure 3, study is DIgSILENT base network shown in Figure 4, summarized as following: No. of Substations 14, No. of Bus bars 25, No. of Lines 18, No. of 2-w Trfs. 18, No. of syn. Machines 15, No. of Asyn. Machines 3, No. of Loads 8, and No. of Shunts 10. It is source of the input data to studied system, two cases are studied to illustrate these variations and its corresponding zone settings applied on two paths P S5S11 and P S9-S8, since (Sx) refer to Substation number.

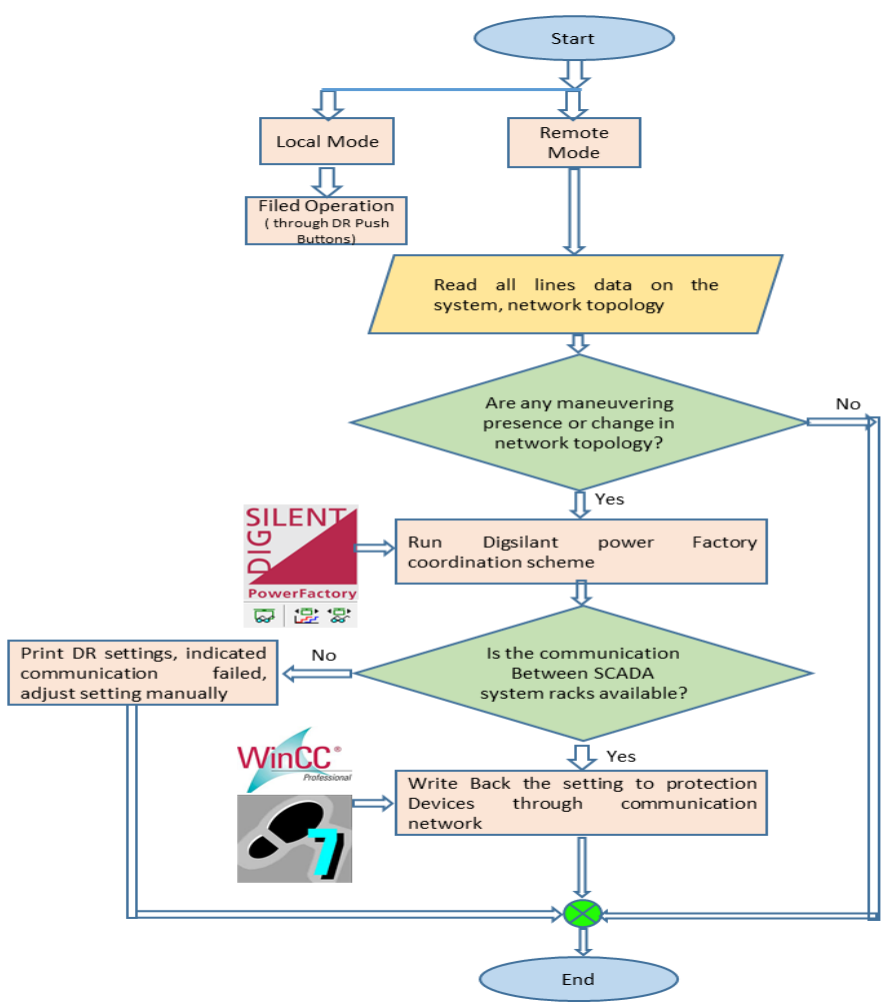

Figure 3. Flow chart for applied sequence 
Polygon distance protection relays are configured according to that paths of the selected transmission lines as shown in Figure 4. DRs settings are according to mentioned in section 2.2. Case studies can be itemized according to change in network topology as following:

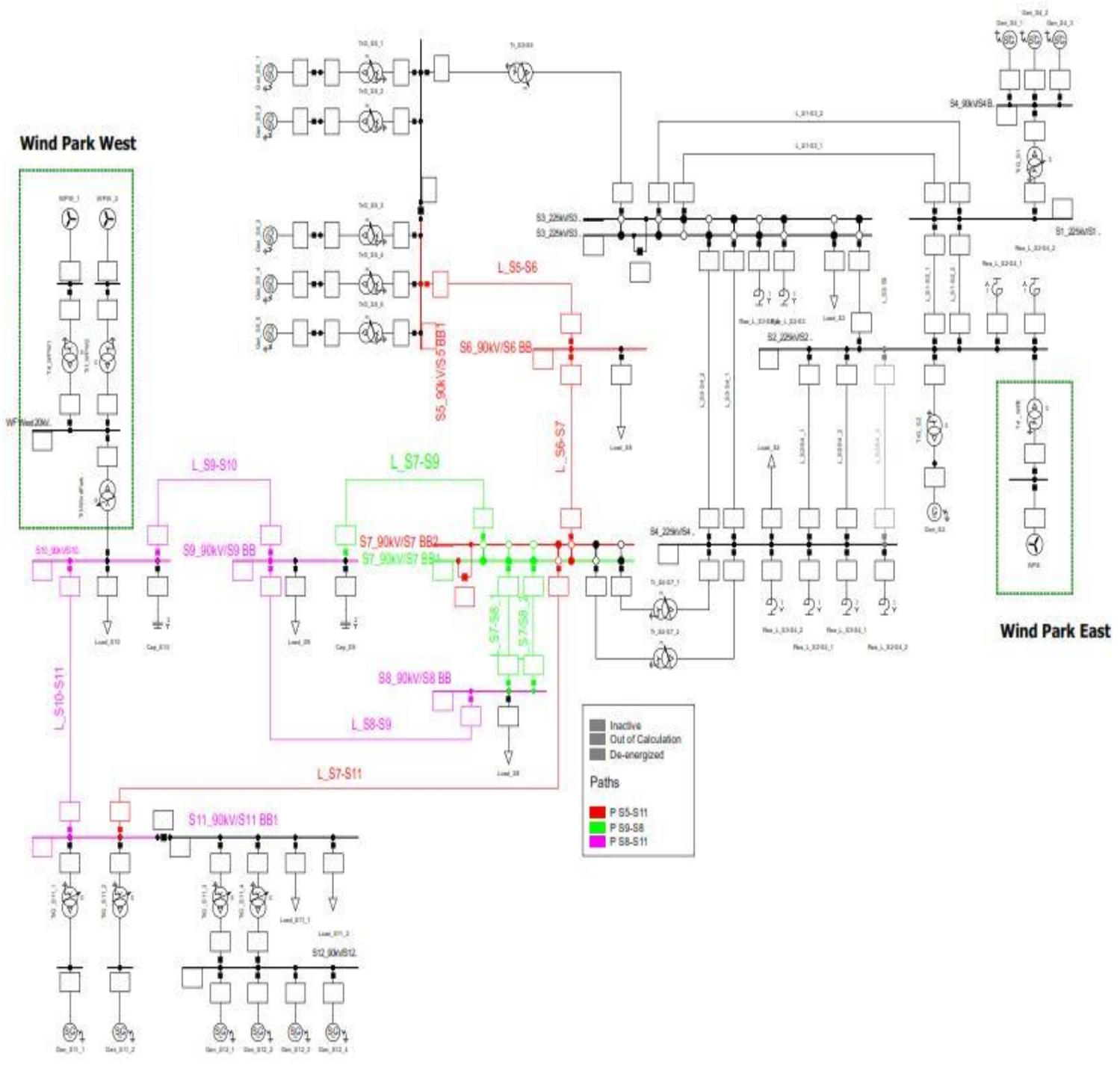

Figure 4. The Electrical Network System

\subsection{Case1-Effect of Variance lengths of lines on DR settings}

This case illustrates setting variation of DR1 placed in Sub.11 path (P S5-S11) when the line (L_S7S9) is out of services, and DIgSILANT coordination assistant is runing according to installed protection devices on the lines.

Table 1 shows parameters of lines having protection devices which the coordination will be executed according to them.

Table 1. Case 1 lines parameters

\begin{tabular}{ccc}
\hline Line & Length, Km & Z, Ohm \\
\hline L_S7-S11 & 150 & 63.89 \\
L_S6-S7 & 150 & 63.86 \\
L_S6-S5 & 100 & 42.607 \\
L_S7-S9 & 10 & 4.578 \\
\hline
\end{tabular}




\subsubsection{Case1-A without change in network topology}

The coordination results are executed in Table 2 column2. When the fault occurs in line L_S6-S7 the faulted impedance picked up the relay is 69.9 pri.Ohm with tripping time $0.74 \mathrm{sec}$. as shown in Figure 5.

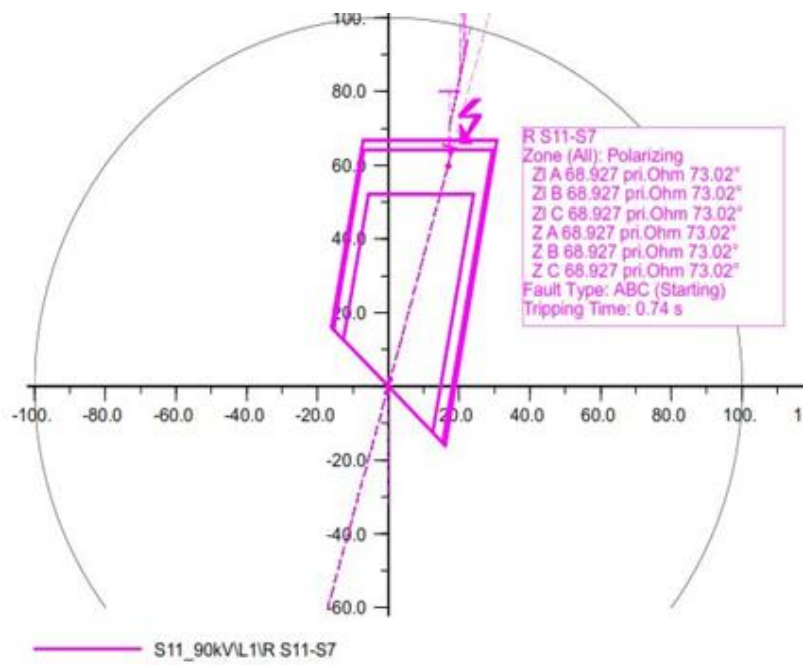

Figure 5. Case1-A R-X plot in case of no change in network toplplogy

Table 2. Case 1 coordination results

\begin{tabular}{ccc}
\hline Zone no. & In case of all lines in service & In case of L_S7-S9 out of service \\
\hline Zone 1 & 54.3 & 54.3 \\
Zone 2 & 66.6 & 102.2 \\
Zone 3 & 69.284 & 136.27 \\
\hline
\end{tabular}

\subsubsection{Case1-B network topology changed}

The coordination results are obtained in Table 2 column3. When the fault occurs in the line L_S6-S7 at the same distance with the same faulted impedance picked up the relay is 69.9 pri.Ohm but with tripping time 0.39 sec. as shown in Figure 6.

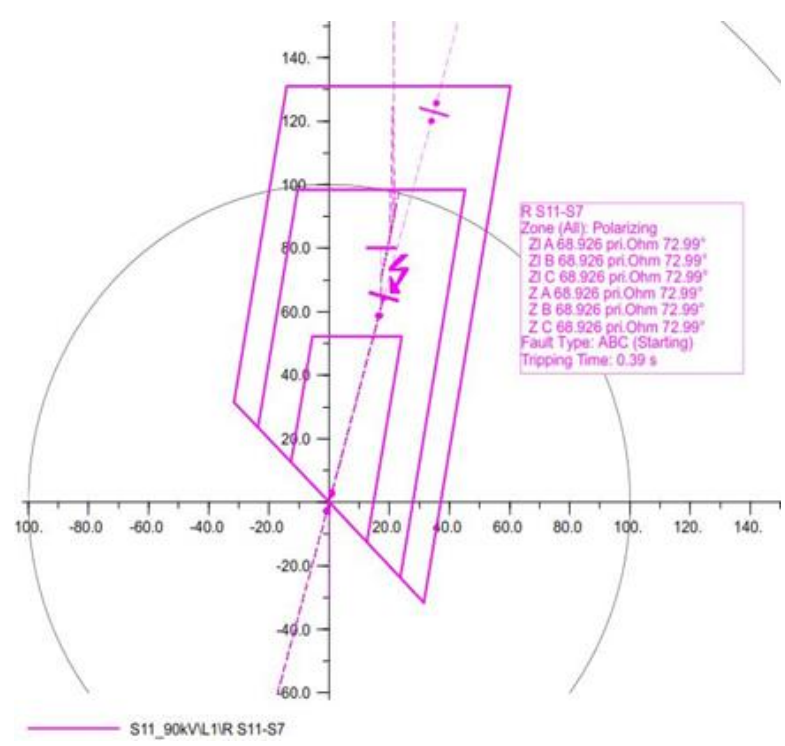

Figure 6. Case1-B R-X plot in case of network topology changed 


\subsection{Case2-Effect of parallel lines outages on DR settings}

For parallel lines, it should be taken into account that the phase settings must be changed [20]. This case illustrates setting variation of DR2 which placed in Sub.9 path (P S9-S8) when the line (L_S7-S8-1) is out of services, DIgSILANT coordination assistant is runing according to the change in the network topology. In Table 3 parameters of lines which used the coordination assistant.

Table 3. Case 2 lines parameters

\begin{tabular}{ccc}
\hline Line & Length, Km & Z, Ohm \\
\hline L_S9-S7 & 10 & 4.57 \\
L_S7-S8-1 & 8 & 3.43667 \\
L_S7-S8-2 & 8 & 3.28 \\
L_S8-S9 & 9 & 4.121 \\
\hline
\end{tabular}

\subsubsection{Case2-A without changing in network topology}

The coordination results are shown in Table 4 column2. When the fault occurs in line L_S7-S8-1 the faulted impedance picked up the relay is 6.6 pri.Ohm with tripping time 0.74 sec. as shown in Figure 7.

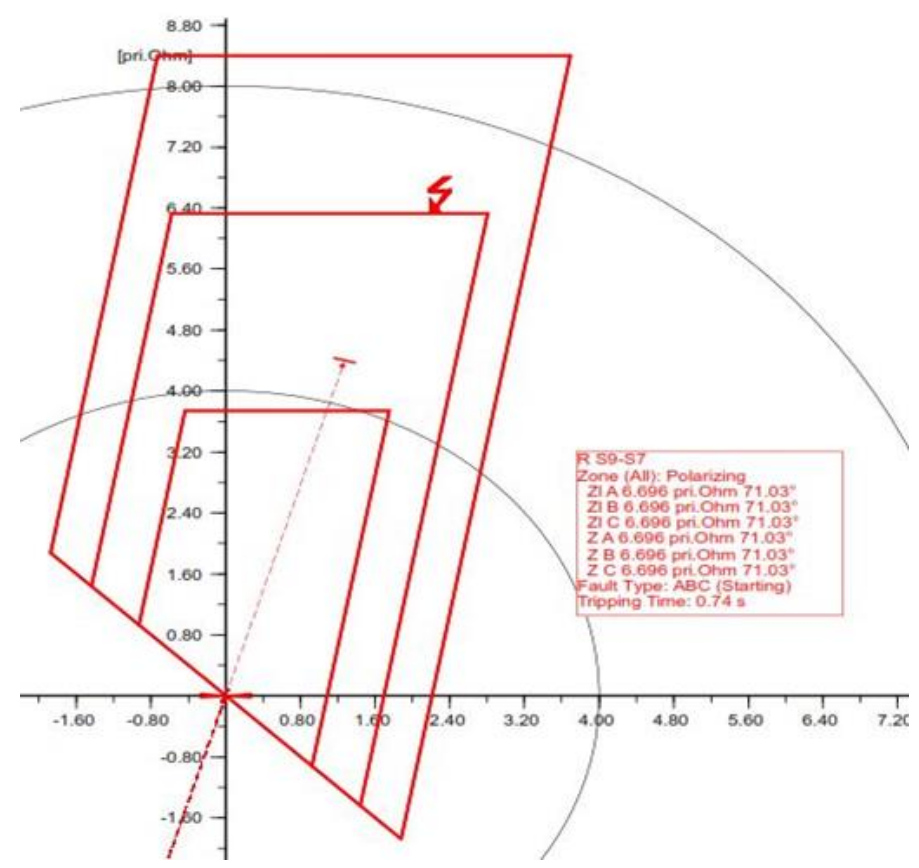

Figure 7. Case2-A R-X plot in case of no change in network toplplogy

Table 4. Case 2 coordination results

\begin{tabular}{ccc}
\hline Zone no. & In case of all lines in service & In case of L_S7-S8-2 out of service \\
\hline Zone 1 & 3.89 & 3.89 \\
Zone 2 & 6.54 & 6.64 \\
Zone 3 & 8.679 & 8.839 \\
\hline
\end{tabular}

\subsubsection{Case2-B network topology changed}

The coordination results are executed in Table 4 column3. Considering L_S7-S8-2 out of servies and the fault occurs in line L_S7-S8-1 at the same distance with the same faulted impedance picked up the relay is 6.6 pri.Ohm but with tripping time $0.39 \mathrm{sec}$. as shown in Figure 8.

These results explain the urgent need for interactive control system executing the relays settings to improve its performance as will be illustrated in practical part. 


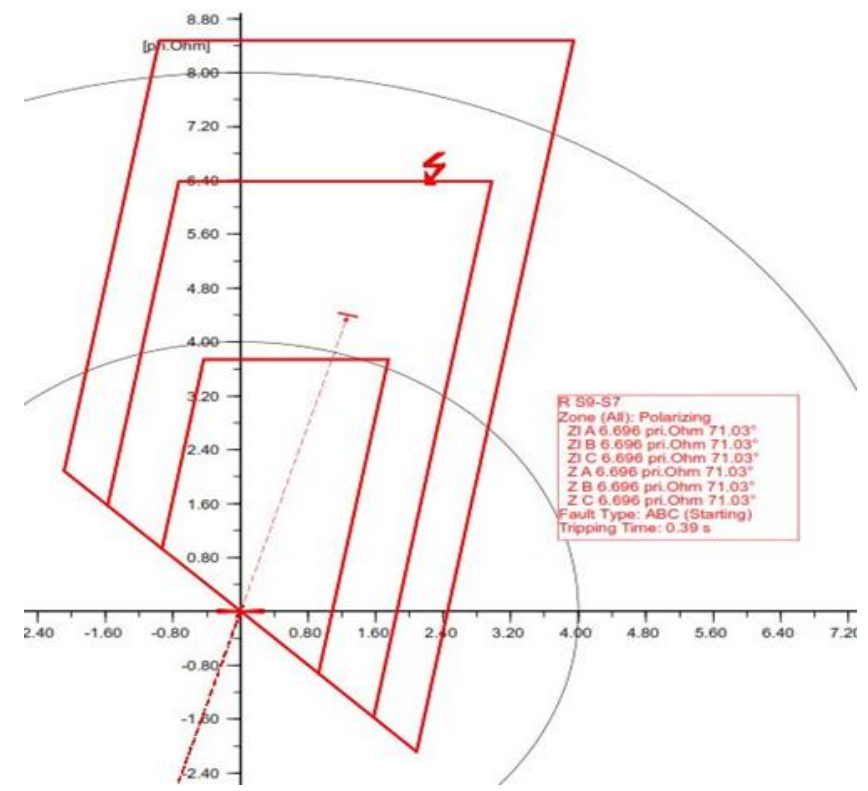

Figure 8. Case2-B R-X plot- in case of network topology changed

\section{PROPOSED PRACTICAL SYSTEM CONFIGURATION AND RESULTS}

A practical representation to enhance protection system performance been done through Siemens hardware and software packages.

\subsection{Hardware devices}

Three Programmable Logic Controllers S7_313C-2DP racks are used. One as master rack reads the DIgSILANT output coordination results, and two others Slaves (DR1 and DR2). Laptop is used as server, plus programming device. Proposed SACDA configuration NetPro communication network is shown in Figure 9.

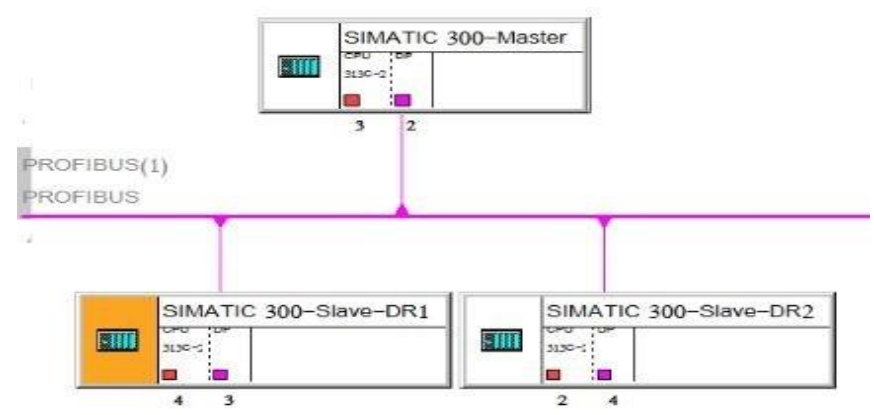

Figure 9. Proposed SCADA configuration in Step7- NetPro

\subsection{Softwares}

SIMATIC STEP 7 V5.5 for PLC programming, WinCC V7.0 for SCADA station programming.

\subsection{Practical system results}

The practical results depend on the output coordination results from DIgSILANT program. Figure 9 represent the actual data sent by master PLC to two slaves (DRs) to enhance its performance as proved in DIgsilant simulation results before. SCADA actual rum time screen shown in Figure 10 (a) with no change in network topology DRs are set automatically. With any change in network topology DRs setting are updated, Figure 10 b illustrates SCADA actual rum time screen when L_S7-S9 out of service DR1 setting automatically changed, and Figure 10c show the online changes in DR2 when L_S7-S8_2 out of servies.

Enhancing the performance of distance protection relays using interactive control ... (Salah K. El-Sayed) 


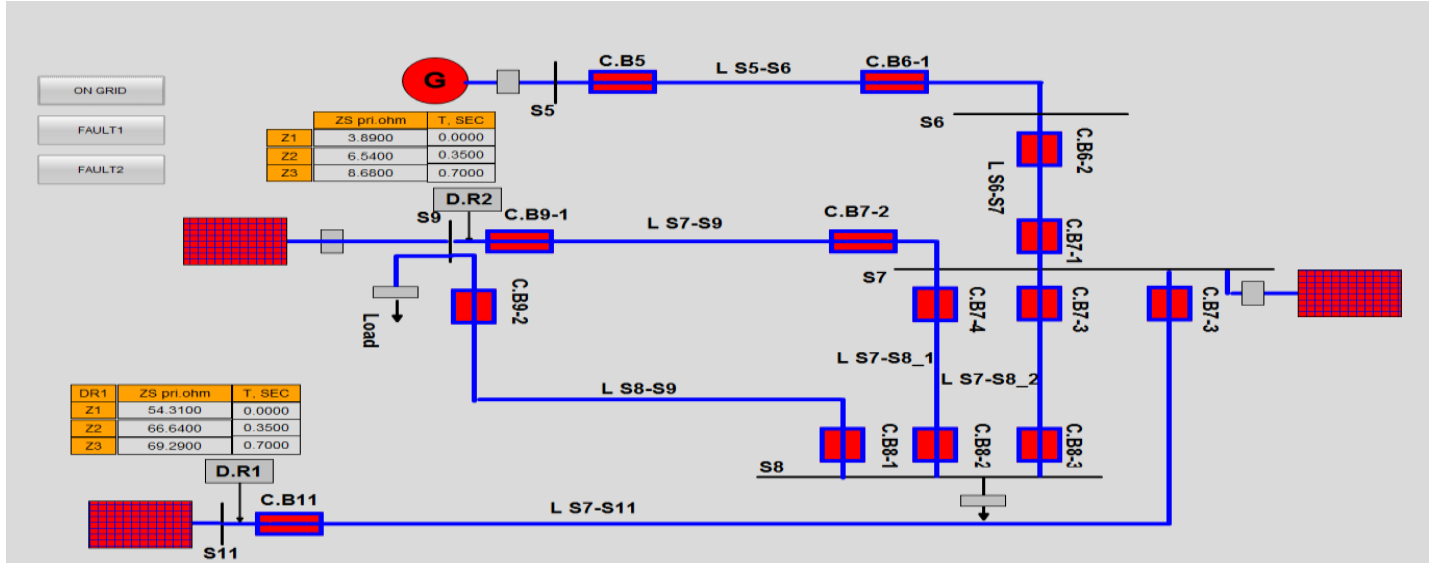

a
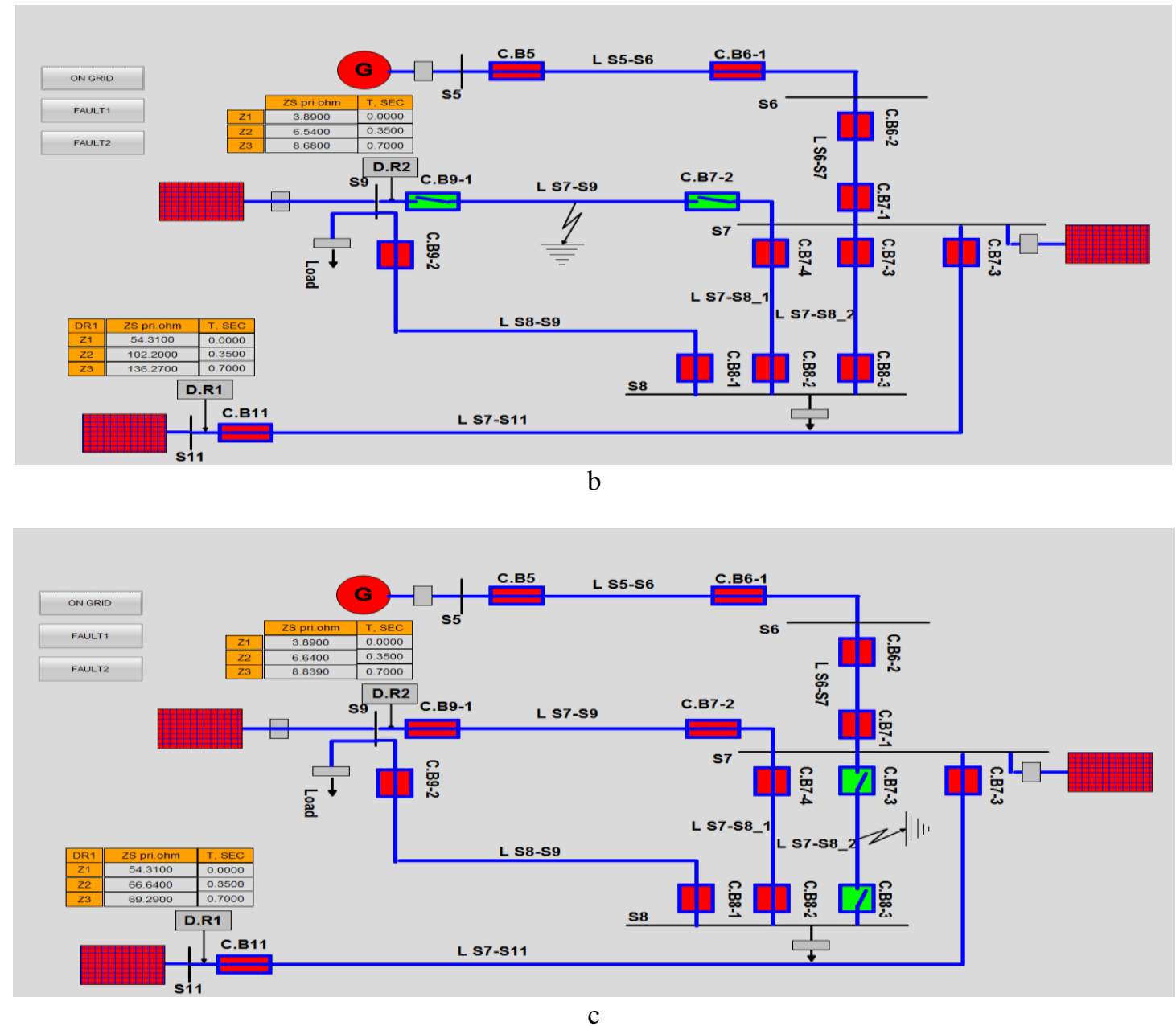

Figure 10. Practical results from WinCC program with considering automatic setting: (a) When no change in network topology; (b) DR1 setting changes in case of line L_S7-S9 out of services; (c) DR2 setting changes in case of line L_S7-S8-1 out of services

\section{CONCLUSION}

Distance relay settings variation due to changing in network topology not limited to faults occurs but may happen during maneuvering of the electrical network parts. There are main features are gained from proposed system added value to enhance protection system decisions. When DRs are linked to simulation program predicts accurate settings, this made protection system more reliable. 
Central SCADA system used for sending data to DRs installed added many features one of them made good coordination between DRs which enhanced the system performance.

\section{REFERENCES}

[1] Blackburn J, Domin T.Protective Relaying principle and application. Francis: CRC Press. 2006.

[2] Horowitz S, Phadke A.power System Relaying. USA: Wiley. 2014.

[3] Jacome Y. An Example Distance Protection Application with Complicating Factors. Presented to Western Protective Relay Conference Spokane. Washington, USA. 2009; 1-12.

[4] Penthong T, Hongesombut K. An Efficient Method of Automatic Distance Relay Settings for Transmission Line Protection. IEEE International Conference of IEEE Region 10 (TENCON 2013). Xi'an, China. 2013; 1-4.

[5] Hong Q, Booth C, Dyko A, Catterson V.Design of an Intelligent System for Comprehensive Validation of Protection Settings. ${ }^{13}$ th International Conference on Development in Power System Protection (DPSP). Edinburgh, UK. 2016; $1-7$.

[6] Escobedo A, Moreno-Centeno E, Hedman W.Topology Control for Load Shed Recovery. IEEE Transactions on Power Systems. 2014; 29(2): 908-916.

[7] Arikan O, Gursanli O, Aydin H, Yagmur E. An Algorithm for Transmission Distance Relay Setting Calculation Under Network Topology Change. IJIREEICE. 2016; 4(5): 508-513.

[8] Yang J, Liao C, Wang Y, Chu C, Lee S, Lin Y. Design and Deployment of Special Protection System for Kinmen Power System in Taiwan. IEEE Transactions on Industry Applications. 2017; 53(5): 4176 - 4185

[9] Jan'icek F, Martin Mucha M. Distance Digital Relay Model Developed In ATP "Foreign Model" and C++. Journal of Electrical Engineering. 2006; 75(5): 268-275.

[10] Bailey D, Wright E.Practical electrical network automation and communication system. Dutch: Elsevier. 2003.

[11] SIPROTEC Distance Protection 7SA6 Manual; V4.6. Dutsh: Siemens. 2004.

[12] Gers J, Holmes E. Protection of electricity distribution networks. UK: IET. 2004.

[13] DIgSILENT Power factory user manual- DIgSILENT. https://www.digsilent.de/en/power-equipment-models.html. accessed 2014.

[14] Saad H, Nagy S, El-Sayed S. Development of EMCS in power plants. JMST. 2015; 2(10): 2680-2686.

[15] Hjorth T, Gupta P, Balasubramanian A. University Implements Distribution Automation to Enhance System Reliability and Optimize Operations. ${ }^{69}$ th Annual Conference for Protective Relay Engineers (CPRE). TX, USA. 2016; 1-8.

[16] Park J, Mackay S. Practical Modern SCADA Protocol. Dutsh: Elsevier. 2004.

[17] Yi Zhang, Y, Ilic D M, Tonguz O. Mitigating Blackouts via Smart Relays: A Machine Learning Approach. IEEE. 2011; 99(1): $94-118$.

[18] IEEE standard association. IEEE Std C37.1. IEEE Standard for SCADA and Automation Systems. New York: IEEE press; 2007.

[19] Gilany M, Hasan B, Malik O. The Egyptian Electricity Authority strategy for distance relay setting: problems and solutions. Elsevier. 2000; 56(2): 89-94.

[20] Nikolovski S, Marić P, Prhal D. Numerical Simulation Of Distance Protection On Three Terminal High Voltage Transmission Lines. International Journal Advanced Engineering. 2009; 32: 195-210. 